\title{
DE LOOPBAAN VAN KRAYENHOFF VAN WICKERA IN SURINAME
}

DOOR

FRED. OUDSCHANS DENTZ

Cornelis Batavus Krayenhoff van Wickera werd 31 December 1794 te Amsterdam geboren uit het huwelijk van Cornelis en Anna Elisabeth Koning. Toen hij den leeftijd van 17 jaar had bereikt, nam hij, op 12 Maart 1812, als soldaat dienst bij de Garde Soldée te Amsterdam. Nederland was sedert 9 Juli 1810 bij Frankrijk ingelijfd. Krayenhoff werd 13 Mei van het volgend jaar tot korporaal bevorderd. Nederlands bevrijding was weldra op handen, en in November 1813 maakten de Kozakken hem krijgsgevangen, toen zij in verschillende provincien van ons land aan deze bevrijding medehielpen.

$\mathrm{Na}$ zijn invrijheidsstelling werd hij in December 1813 tot sergeant bij het Bataljon der Infanterie van Linie no. 13 bevorderd.

Als 19-jarige sergeant deelnemend aan den slag bij Waterloo, onderscheidde hij zich dusdanig, dat hij bij koninklijk besluit van 17 Augustus 1815 no. 77 tot ridder 4de klasse in de Militaire Willemsorde werd benoemd, welk eereteeken 30 April van dat jaar door Willem I was ingesteld.

Vier jaar later, op 28 Juli 1817, werd hij tot sergeant majoor, en in September 1820 tot adjudant-onderofficier bevorderd. Zijn officiersrang bereikte hij, toen hij op 16 Augustus 1822 tot 2de luitenant bij de 9de afdeeling infanterie werd benoemd.

Hij meldde zich in 1827 aan om naar Suriname te worden gezonden, waar hij 6 Juli van dat jaar werd ingedeeld bij het Bataljon Jagers no. 27. Thans ving voor den jongen officier en ridder zijn loopbaan in zijn tweede vaderland aan, waar hij op 66-jarigen leeftijd kwam te overlijden.

Een jaar na zijn aankomst maakte hij plannen om in het huwelijk te treden met Barbara Geertruida Wolff, die 21 Maart 1825 uit Amsterdam in Suriname was aangekomen in gezelschap van 
eenige familieleden van mr. J. A. Swaen $\left.{ }^{1}\right)$. Zij was een dochter van de weduwe D. Wolff ${ }^{2}$ ), vóór haar huwelijk Margaretha Johanna Juliaans, op 28 Mei 1767 te Utrecht gedoopt. Na het overlijden van den heer Wolff trad zij voor de tweede maal in het huwelijk met mr. Johannes Aleydus Swaen.

In het huwelijksregister 1824-1835 van Suriname lezen wij de volgende inschrijving:

Op heden den 1 Augustus 1828 zyn ten overstaan van den Weled. Gestr. Heer President van het Gemeentebestuur der Kolonie Suriname,

1) Mr. Johannes Aleydus Swaen, planter in Demerary, eigenaar van de plantage Poederoyen aldaar, geboren 17 Februari 1774, overleden te Paramaribo 21 November 1820. Hij vertrok van Demerary en vestigde zich in Suriname. In het register van aangekomen passagiers in Suriname 1816-1825 staat vermeld, dat mr. Swaen en gezin op 14 October 1816 met het schip , ,De Goede Verwachting” van Amsterdam in Suriname is aangekomen. Met den heer J. C. Wolff Juliaans, zijn stiefzoon, legde hij de plantage ,Aleyda” in het district Cottica aan, een suikerplantage van 1000 akkers, gelegen tusschen "Carelsburg" en „,Langmoedigheid”. Volgens de Surinaamsche Almanak van 1821, blz. 45, waren daarvan in genoemd jaar eigenaars: Wed. Bedloo geboren Meyer, J. de Boer, J. J. Bronovo n. ux, G. A. Entink n. Ux, Wed. Roux geboren Bedloo, J. A. Swaen n. ux en M. A Wolff. In Demerary woonde nog Anthony Peter Swaen, raad van Justitie, gehuwd met Maria Wossinck. Hun zoon Ernst Sigismund werd 15 April 1801 in Demerary geboren.

2) Een zoon uit haar eerste huwelijk, Cornelis Johannes, in 1796 te Utrecht geboren, noemde zich Wolff Juliaans, vestigde zich in Suriname, waar hij planter werd. Hij overleed ongehuwd op 17 Januari 1857 in het huis Saramaccastraat L.E. no. 34. In het district Saramacca was Wolff Juliaans, die ook diaken van Herv. gemeente was, burgerkapitein. Over diens ,,verregaande slegte Orde en Slordigheid” in de behandeling van zaken in de divisie raadplege men de notulen van het verhandelde en geresolveerde in de vergadering van den Kolonialen raad van 8 Maart en 10 Mei 1836. Ofschoon de heemraad van het district voorstelde hem te ontslaan, omdat hij ook ,,wegens voortdurende ongesteldheid of andere oorzaken, niet in staat is de aangelegenheden der divisie naar behooren waar te nemen" werd hieraan geen gevolg gegeven, maar werd hij ernstig aangemaand ,,zich voor het vervolg meer toe te leggen op de stipte volbrenging zijner ambtspligten en bekomen orders van den Heemraad". De meerderheid van de leden van den raad schreef de gepleegde verzuimen ,,meer toe aan negligentie en toevallige omstandigheden dan aan kwaden wil”. ,En aangezien de betrekking van burgerkapitein zoo moeylyk te vervullen is,, zeggen de notulen - ,terwyl het ontslag van eenen uithoofde van verzuimenissen wel ligt aanleiding aan anderen zoude kunnen geven om ook zich daaraan schuldig te maken, ten einde zoodoende ontslagen te raken van eene betrekking waaraan veelvuldige moeyelyke en onaangename werkzaamheden verbonden zyn", was men tegen ontslag. 
door my ondergeteekende tweede kommies, na behoorlyke afvraging in den huwelyken staat aangeteekend:

Den Weled.Gestr. Heer Cornelis Batavus Krayenhoff van Wickera, tweede luitenant by het Batt. Jagers No. 27, jongeman, oud 34 jaren, geboren te Amsterdam, met Mej. Barbara Geertruida Wolff, jongedochter, oud 31 jaren, geboren te Utrecht en beide van de Herv. gemeente.

Overleggende eene resolutie van Z.E. den Heere Schout by Nacht, Gouverneur-Generaal over de gezamenlyke Nederlandsche W.I. Bezittingen dd 5 Juni ll. waaruit consteert dat door Z.E. den Kommissaris-Generaal van Z.M. voor de W.I. Bezittingen aan den Bruidegom verlof is verleend tot het aangaan van een wettig huwelyk, alsmede eene resolutie van gemelde Z.E. den Heere Gouverneur-Generaal dd 28 July 11 , waarby aan de comparanten dispensatie volgens de tyd van inwoning is verleend.

Actum Paramaribo dat. ut supra.

In kennisse van my
G. A. Röhnisch Scheper
2de Commies,
L. S. Slengaarde
President.

Certificeere, dat de Huwelyksvoltrekking (tengevolge de hiernevenstaande aanteekening dd 1 Augustus) geen plaats heeft kunnen hebben uit hoofde dat de Bruid Mejuffrouw Barbara Geertruida Wolff op den tienden dezer maand is overleden.

Actum Paramaribo, den 17 Augustus 1828.

G. A. Röhnisch Scheper 2de Commies.

Uit het huwelijk van mr. Swaen met de weduwe Wolff werd een dochter geboren $\left.{ }^{1}\right)$ Theodora Aleyda, die als achttienjarige met hetzelfde schip als Barbara Wolff met haar moeder van Amsterdam in Suriname terugkwam. Toen nu Krayenhoff van Wickera opnieuw huwelijksplannen koesterde, viel zijn oog op haar, en hij trad met deze, in 1807 op „Poederoyen” in Demerary geboren, 12 jaar jongere dochter van $\mathrm{mr}$. Swaen in het huwelijk. Den 25sten September 1829 had de aanteekening plaats, waarbij de bruidegom een extract van den minister voor de Marine en van Koloniën van 6 Juli L.K. no. 79 overlegde, zoowel als de resolutie van den gouverneur-generaal van den 30sten Juli no. 380 , waarbij tot het huwelijk toestemming gegeven werd; de bruid legde de toestemming van mevrouw de weduwe Swaen over. Mr. Swaen, die gelijk gezegd, toen reeds overleden was, ligt

1) Een zoon Jan Aleydus Swaen, in 1803 te Nijmegen geboren, overleed te Paramaribo in het huis Combé No. 108/109 op 1 Mei 1831, en een andere zoon L. A. Swaen op 10 September 1827. 
begraven op zijn plantage „Katwijk” in het district BenedenCommewyne ${ }^{1}$ ).

Ofschoon het huwelijk op 7 October was vastgesteld, werd het tengevolge van ongesteldheid van den bruidegom eerst 11 November 1828 voltrokken ${ }^{2}$ ).

Nadat Krayenhoff van Wickera tot 1ste luitenant was bevorderd, benoemde de gouverneur-generaal hem tot landdrost in het Nederdistrict Nickerie, in verband met de schorsing van den toenmaligen functionaris D. Boonen. Krayenhoff werd provisioneel op 4 Juli 1838 met de waarneming van dit ambt belast op een traktement van $f 2000$, benevens de toelage van $f 20$ 's maands voor de directie van het genie-departement. Tevens werd hij president van den raad van hoofdingelanden ${ }^{3}$ ).

Wij zien hem in 1839 als kapitein genoemd en in die hoedanigheid veel voldoening geven, blijkende uit de resolutie van den gouverneur-generaal van 30 November 1842 no. 1611, waarbij hij dank voor zijn ijver en de belangstelling in zijn militaire functie ontving ${ }^{4}$ ). Deze resolutie luidde:

Gelezen hebbende eene missive van den Majoor der Artillerie T. L. de Casembroot, dd 22 November 11 , no. 278 ,

Daarby inzendende het rapport van de door ZynEdgestr. tengevolge der Gouvernements order van 19 October tevoren no. 211 gehouden inspectie der posten langs het cordon van binnenlandsche defensie, met voorstel wyders om tot bevordering van de dienst en ter aanmoediging, den kapitein Krayenhoff van Wickera de tevredenheid van den Gouverneur-Generaal te betuigen voor den yver en de belangstelling, waarmede hy de aan hem opgedragen werkzaamheden van het Geniedepartement op den linkervleugel van het cordon waarneemt;

Gelet... enz.

1) De grafzerken van Swaen en echtgenoote heb ik op de plantage „Katwyk" onder den vloer van een loods aangetroffen. $Z_{i j}$ vermelden het volgende: „Mr. Johannes Aleydus Swaen V.H. Heer van Poederoyen, geboren den 17e February 1774, overleden den 21 e November 1820, voerende zestien kwartieren” en , Rustplaats van wyle vrouwe Margaretha Johanna Swaen gebooren Juliaans, overleden 27 July 1843 in den ouderdom van 76 jaar". Zij was te Paramaribo overleden in het huis 1ste Buitenwijk no. 37 en op plantage begraven.

$\left.{ }^{2}\right)$ Krayenhoff van Wickera en bruid gaven per brief van 11 November 1829 van hun voorgenomen huwelijk kennis aan mr. E. S. Swaen, wonende op de hofstede ,,Amstelrust” bij Ouderkerk aan den Amstel (Archief prof. dr. A. B. E. H. Swaen te Amsterdam).

s) Journaal van het verhandelde en geresolveerde by den Gouverneur-Generaal ad interim der Ned. W.I. Bezittingen 4 Juli 1838, no. 693.

4) Resolutie van 30 November 1842 , no. 1611 . 
Heeft goedgevonden en verstaan:

a. enz.

b. Aan den Kapitein by het Bataillon Jagers no. 27 Krayenhoff van Wickera, by extract dezes, des Gouverneur-Generaals tevredenheid te betuigen over de gunstige rapporten ten zynen aanzien ontvangen, welke in aanmerking zullen worden genomen en daar waar zulks mogt te pas komen, enz.

In verband met een oogziekte vertrok Krayenhoff van Wickera in 1845 met ziekteverlof naar Nederland. Dit verlof werd verlengd tot 30 April $1846^{1}$ ). Per ,Prins Willem Frederik Hendrik” keerde hij in April met gezin uit Nederland in Suriname terug ${ }^{\mathbf{1}}$ ).

Twee jaar later werd hij naar Curaçao overgeplaatst, waar hij 13 Maart 1848 in de sterkte werd gebracht en bij Zijner Majesteits besluit van 19 September 1849 no. 52 tot majoor bevorderd. Drie jaar later nam hij ontslag uit den dienst, dat hem bij K.B. van 28 Maart 1856 no. 42 werd verleend.

Zijn hart trok naar Suriname terug. Hij vestigde zich in het district Coronie, zooals het Nederdistrict Nickerie toen werd genoemd. De gouverneur benoemde hem andermaal tot landdrost. Hij bekleedde dit ambt tot 1859 , toen hij naar Paramaribo vertrok, waar hij als ambteloos burger tot zijn dood op 8 April 1861 bleef wonen. Hij overleed aldaar in het huis Zwartenhovenbrugstraat L.B. no. 179.

Vóór zijn vertrek naar Curaçao had hij zijn slaaf Johannes vrijgekocht, aan wien bij die gelegenheid van manumissie den naam van Johannes Petrus Krayenburg werd geschonken ${ }^{3}$ ).

\section{BRONNEN}

Krijgsgeschiedkundig Archief te 's-Gravenhage, Archief van Suriname in het Alg. Rijksarchief 's-Gravenhage, familiepapieren van prof. dr. A. E. H. Swaen te Amsterdam.

1) Journaal van het verhandelde en geresolveerde bij den Gouverneur der kolonie Suriname van 1 April 1846, no. 402.

$\left.{ }^{2}\right)$ Missive van den minister van Koloniën van 25 April 1846, no. 30/66. Resolutie van den gouverneur van 26 Juni 1836, no. 924.

3) Bij resolutie van 14 November 1843 , no. 1415 . 